\title{
Flow-dependency of exhaled nitric oxide in children with asthma and cystic fibrosis
}

\author{
A. Kroesbergen"*, Q. Jöbsis ${ }^{\#}$, E.H.D. Bel*, W.C.J. Hop**, J.C. de Jongste ${ }^{\#}$
}

Flow-dependency of exhaled nitric oxide in children with asthma and cystic fibrosis. A. Kroesbergen, Q. Jöbsis, E.H.D. Bel, W.C.J Hop, J.C. de Jongste. (C)ERS Journals Ltd 1999. ABSTRACT: The concentration of nitric oxide in exhaled air, a marker of airway inflammation, depends critically on the flow of exhalation. Therefore, the aim of this study was to determine the effect of varying the flow on end-expiratory NO concentration and NO output in children with asthma or cystic fibrosis (CF) and in healthy children.

Nineteen children with stable asthma, 10 with CF, and 20 healthy children exhaled from TLC while controlling expiratory flow by means of a biofeedback signal at approximately $2,5,10$ and $20 \%$ of their vital capacity per second. NO was measured in exhaled air with a chemiluminescence analyser. Comparisons between the three groups were made by analysing the NO concentration at the endexpiratory plateau and by calculating NO output at different flows.

Exhaled NO decreased with increasing flow in all children. Children with asthma had significantly higher NO concentrations than healthy children, but only at the lowest flows. Asthmatics using inhaled steroids $(n=13)$ tended to have lower median exhaled NO than those without steroids. The slope of linearized (log-log transformed) NO/flow plots was significantly steeper in asthmatics than in healthy controls. CF patients had a significantly lower NO concentration and output over the entire flow range studied, compared to asthmatic and control subjects, with a similar NO/flow slope as control subjects.

In conclusion, the nitric oxide concentration in exhaled air is highly flow-dependent, and the nitric oxide-flow relationship differs between asthmatics versus cystic fibrosis patients and control subjects. Assessment of the nitric oxide/flow relationship may help in separating asthmatics from normal children.

Eur Respir J 1999; 14: 871-875.

\begin{abstract}
\#Erasmus Medical Center/Sophia Children's Hospital, Dept of Paediatrics, Division of Paediatric Respiratory Medicine and **Epidemiology and Biostatisties, Dir. Molewaterplein 60, 3015 GJ Rotterdam, the Netherlands; *Dept. of Pulmonology, Leiden University Medical Center, Albinusdreef 2.2333 ZA Leiden, the Netherlands.
\end{abstract}

Correspondence: J.C. de Jongste

Sophia Children's Hospital

Dr Molewaterplein 60

3015 GJ Rotterdam

the Netherlands

Fax: 31104636801

\section{Keywords: Asthma \\ children \\ cystic fibrosis \\ exhaled air \\ flow dependency \\ nitric oxide}

Received: June 301998

Accepted after revision May 181999

This work was supported by grant number 94.14 from the Dutch Asthma Fund.
Nitric oxide (NO) has an important regulatory role in the lung and has been implicated in the pathophysiology of airway diseases [1]. During the past few years, NO in exhaled air has been examined as a marker of airway inflammation. NO can be measured directly in exhaled air [2]; increased levels have been documented in several inflammatory airway disorders, including asthma. However, patients with cystic fibrosis $(\mathrm{CF})$ were found to have similar or lower levels compared to normal subjects, either in nasal or in oral air [3, 4]. Both an increase and a decrease in the level of $\mathrm{NO}$ in exhaled air may therefore be taken as potential markers of disease and exhaled NO may be clinically useful in diagnosing and monitoring airway diseases.

Values of exhaled NO reported by various investigators differ greatly [5]. This can be explained by differences in the methods of measurement. NO in exhaled air depends on airflow [6]. Since NO is continuously released into the airway lumen, high concentrations will result when exhalation is slow, and low concentrations when exhalation is fast. It is unknown to what extent disease affects the flow-dependency of NO in exhaled air. Recently, European Respiratory Society task force published guidelines on measurement of exhaled NO, emphasizing that normalization for flow is vital [7]. Until now, studies on exhaled NO in children did not take flow-dependency into account. Therefore, the aim of this study was to determine the effect of varying the flow of exhalation on the NO concentration in exhaled air, and to examine the concentration of $\mathrm{NO}$ and the $\mathrm{NO} /$ flow relationship in normal subjects, asthmatic children and children with CF.

\section{Patients and methods}

\section{Study population}

Patients were recruited from the outpatient clinic for paediatric respiratory medicine of Sophia Children's Hospital, and healthy control subjects were selected from a school population according to the following criteria. Asthma was diagnosed according to international guidelines, based on a typical clinical history [8]. In addition, all asthmatic children had bronchial hyperresponsiveness (provocative dose of inhaled methacholine that produced a $20 \%$ fall in forced expiratory volume in one second of $<150 \mu \mathrm{g}$ ) and allergy, as previously documented by radio allergosorbent test class $\geq 2$ for at least one common airborne allergen. All asthmatics were clinically stable for at least 2 weeks before the measurement, and all were 
lifelong nonsmokers. Thirteen used inhaled corticosteroids (median daily dose $400 \mu \mathrm{g}$, range 100-1,000 $\mu \mathrm{g}$. day $\left.^{-1}\right)$, all used bronchodilators on demand. CF was diagnosed on the basis of typical clinical symptoms, abnormal sweat test and the identification of two CF mutations. All CF patients had been clinically stable for at least 2 weeks prior to the measurements. One CF patient used inhaled corticorsteroids. Healthy children were selected on the basis of no history of allergic respiratory disease and eczema, as defined by negative answers to the International Study on Allergies and Asthma in Childhood (ISAAC) core questionnaires, no symptoms of respiratory infection during the past 2 weeks, never smoked and had no other chronic disease. All had a normal lung function. None used medication. All subjects underwent flow volume curve measurements, using a heated Lilly-type pneumotachograph (Jaeger, Würzburg, Germany); results were expressed as per cent predicted [9]. The study was approved by the hospital ethics committee and informed consent was obtained from all subjects.

\section{Nitric oxide measurement}

NO was measured in exhaled air with a Sievers 280 chemiluminescence analyser (Sievers, Boulder, CO, USA) with a sensitivity of $<0.1$ parts per billion ( $\mathrm{ppb}$ ) and a detection range of $<0.1-500,000 \mathrm{ppb}$. The sampling flow was $0.2 \mathrm{~L} \cdot \mathrm{min}^{-1}$, the response time was $0.2 \mathrm{~s}$ and data were displayed with a lag time of $\sim 2 \mathrm{~s}$. The analyser was calibrated regularly according to the manufacturer's guidelines, employing certified calibration gases containing 0 $\mathrm{ppb}, 100 \mathrm{ppb}$ and 9 parts per million (ppm) NO (HoekLoos, Barendrecht, the Netherlands). The measurement circuit consisted of a mouthpiece connected to a two-way nonrebreathing valve (Rudolph Inc., Kansas City, MO, USA) through which the subjects inhaled ambient air while seated and without wearing a noseclip. After inserting the mouthpiece, the subjects inhaled to total lung capacity (TLC and immediately exhaled for as long as possible into a wide bore tube, with an in-line flow resistance (model \#7100 R-20, $20 \mathrm{cmH}_{2} \mathrm{O} \cdot \mathrm{L}^{-1} \cdot \mathrm{s}$; Rudolph Inc). This was performed at flows corresponding to 2, 5, 10 and $20 \%$ of the subject's vital capacity (VC) per second. A fine bore teflon tube continuously sampled the exhaled air from a side-port directly after the mouthpiece at $0.20 \mathrm{~L} \cdot \mathrm{min}^{-1}$ for the measurement of NO. Airflow was measured by a heated Lilly-type pneumotachograph (Jaeger), mounted after the resistance. Flow was displayed on a video screen as a moving block that could be seen by the subject and should be kept between two arrows. This biofeedback system made it possible to standardize exhaled flow to an individually set value. An end-expiratory flow-plateau of at least $3 \mathrm{~s}$ for the different flows ( $2 \mathrm{~s}$ for the highest flow) was the end-point of the measurement. A plateau was defined as a flow tracing which varies less than $\pm 10 \%$ around the target flow. The test was performed in triplicate for every flow and average NO values at the flow plateau were calculated. Between the different manoeuvres, a resting period of 2-3 min was maintained for equilibration of resting ventilatory conditions. All tests were performed with ambient NO concentrations $<5 \mathrm{ppb}$.

\section{Data analysis}

Both the NO signal and the flow signal were fed into a computer at a sampling rate of $20 \mathrm{~Hz}$. Values of $\mathrm{NO}$ and flow were obtained at each attempt by calculating the mean value in defined time intervals of 3 or $2 \mathrm{~s}$, using custom-made software, and individual means were calculated from triplicate NO and flow $\left(\mathrm{L} \cdot \mathrm{s}^{-1}\right)$ values. NO output, defined as the product of mean NO and flow (L. $\mathrm{s}^{-1}$ ), was calculated for each target flow, and expressed in $\mathrm{nL} \cdot \mathrm{min}^{-1}$. NO concentrations and NO output values were lognormally distributed and compared for each of four target flows between patient groups and healthy control subjects by means of the Mann-Whitney test. Plots of NO versus flow in $\mathrm{L} \cdot \mathrm{s}^{-1}$ were linearized by log-log transformation, and regression analysis for repeated measurements was used to compare $\mathrm{NO}$ /flow slopes for the three groups [10]. The effect of normalizing flow for VC was evaluated by plotting individual $\mathrm{NO}$ values versus flow, either expressed as $\% \mathrm{VC} \cdot \mathrm{s}^{-1}$ or as $\mathrm{mL} \cdot \mathrm{s}^{-1}$, in $\log -\mathrm{log}$ normalized plots. Standard deviations of the intercepts of individual regression lines in both types of $\mathrm{NO} /$ flow plots at an arbitrary flow of $\log \left(7 \% \mathrm{VC} \cdot \mathrm{s}^{-1}\right)$ and $\log (300$ $\left.\mathrm{mL} \cdot \mathrm{s}^{-1}\right)$ were compared. The level of significance was set at $\mathrm{p}=0.05$ (two sided).

\section{Results}

Patient characteristics are given in table 1. The measurements were well tolerated. Two or three reproducible $\mathrm{NO}$ values for each flow rate were always obtained within five attempts. The NO level at the end-expiratory plateau decreased with increasing flows in all children. Median values of NO concentration and NO output, as well as the median absolute flows at which these were obtained, are given in table 2. Individual NO-flow relationships for the three groups are shown in figure 1. Asthmatics had higher median NO concentrations than control subjects, but a significant difference was only present at the lowest end of the flow spectrum. Likewise, median NO output was higher in asthmatics than in control subjects at the lower end of the flow range, but the differences were not significant. Strikingly, the variation in exhaled NO was much larger in asthmatics than in healthy children, Median NO values were higher in asthmatics without corticosteroids than in those with steroids $(12.1,6.1,4.2$ and 2.7 ppb versus $16.7,17.1,11.1$, and $6.8 \mathrm{ppb}$ at flows of 2 ,

Table 1. - Patient characteristics

\begin{tabular}{lccc}
\hline & $\begin{array}{c}\text { Healthy control } \\
\text { subjects }\end{array}$ & $\begin{array}{c}\text { Asthmatic } \\
\text { children }\end{array}$ & CF patients \\
\hline Subjects $\mathrm{r}$ & 20 & 19 & 10 \\
Sex M/F & $12 / 8$ & $9 / 10$ & $5 / 5$ \\
Age months & $165 \pm 10$ & $154 \pm 22$ & $143 \pm 22$ \\
& $(149-180)$ & $(116-198)$ & $(114-183)$ \\
FVC \% & $101 \pm 12$ & $101 \pm 12$ & $94 \pm 13$ \\
& $(82-122)$ & $(76-121)$ & $(78-126)$ \\
FEV1\% & $103 \pm 12$ & $88 \pm 16$ & $84 \pm 17$ \\
& $(85-126)$ & $(54-116)$ & $(52-110)$ \\
\hline
\end{tabular}

Data are mean \pm SD (ranges). CF: cystic fibrosis; M: male; F: female; FVC: forced vital capacity; FEV1: forced expiratory volume in one second. 
Table 2. - Exhaled nitric oxide (NO) in children with and without asthma or cystic fibrosis (CF)

\begin{tabular}{|c|c|c|c|}
\hline & $\begin{array}{l}\text { Healthy control subjects } \\
\qquad(\mathrm{n}=20)\end{array}$ & $\begin{array}{l}\text { Asthmatic children } \\
\qquad(\mathrm{n}=19)\end{array}$ & $\begin{array}{l}\mathrm{CF} \text { patients } \\
(\mathrm{n}=10)\end{array}$ \\
\hline \multicolumn{4}{|l|}{ Exhaled NO ppb } \\
\hline At $2 \% \mathrm{VC} \cdot \mathrm{s}^{-1}$ & $8.8(5.4-23.6)$ & $12.1(1.7-75.1)^{*}$ & $3.5(0.4-9.9)^{* *}$ \\
\hline At $5 \% \mathrm{VC} \cdot \mathrm{s}^{-1}$ & $5.9(3.6-13.9)$ & $6.4(1.0-36.8)$ & $1.9(0.6-4.3)^{* *}$ \\
\hline At $10 \% \mathrm{VC} \cdot \mathrm{s}^{-1}$ & $4.8(2.6-10.0)$ & $4.6(1.1-21.3)$ & $1.5(0.2-3.6)^{* *}$ \\
\hline At $20 \% \mathrm{VC} \cdot \mathrm{s}^{-1}$ & $4.4(3.2-6.6)$ & $3.2(0.9-18.5)$ & $1.4(0.4-2.6)^{* *}$ \\
\hline \multicolumn{4}{|c|}{ NO output $\mathrm{nL} \cdot \mathrm{min}^{-1}$} \\
\hline At $2 \% \mathrm{VC} \cdot \mathrm{s}^{-1}$ & $39(17-107)$ & $64(6-271)$ & $11(1-35)^{* *}$ \\
\hline At $5 \% \mathrm{VC} \cdot \mathrm{s}^{-1}$ & $65(35-195)$ & $72(7-320)$ & $15(3-40) * * *$ \\
\hline At $10 \% \mathrm{VC} \cdot \mathrm{s}^{-1}$ & $102(60-241)$ & $109(15-357)$ & $27(5-45)^{* * *}$ \\
\hline At $20 \% \mathrm{VC} \cdot \mathrm{s}^{-1}$ & $190(113-368)$ & $151(24-650)$ & $43(16-83)^{* * *}$ \\
\hline \multicolumn{4}{|c|}{ Actual flows $\mathrm{mL} \cdot \mathrm{s}^{-1}$} \\
\hline At $2 \% \mathrm{VC} \cdot \mathrm{s}^{-1}$ & $70(40-120)$ & $60(30-300)$ & $52(30-200)$ \\
\hline At $5 \% \mathrm{VC} \cdot \mathrm{s}^{-1}$ & $170(100-300)$ & $150(70-270)$ & $123(90-210)$ \\
\hline At $10 \% \mathrm{VC} \cdot \mathrm{s}^{-1}$ & $341(200-610)$ & $283(160-540)$ & $272(160-410)$ \\
\hline At $10 \% \mathrm{VC} \cdot \mathrm{s}^{-1}$ & $716(420-1210)$ & $570(340-1070)$ & $556(360-740)$ \\
\hline
\end{tabular}

All data are median (range). VC: vital capacity; ppb: parts per billion. *: $\mathrm{p}<0.05 ; * *: \mathrm{p}<0.001 ; * * *: \mathrm{p}<0.0001$ compared to control subjects and asthmatics.

5, 10 and $20 \%$ of $\mathrm{VC}$, respectively), but none of the differences reached statistical significance. $\mathrm{CF}$ patients had a significantly lower median NO concentration and output than healthy control subjects and asthmatics over the entire flow range tested. Double logarithmic transformation of flow and $\mathrm{NO}$ resulted in a linear $\mathrm{NO} /$ flow relationship for each individual in all three groups within the flow range studied (fig. 1). Using regression analysis of $\log$ NO versus $\log$ flow, with flow expressed as $\mathrm{mL} \cdot \mathrm{s}^{-1}$, it appeared that the average decrease of NO per doubling of flow in asthmatics was 33\% (95\% confidence interval (CI) 29-37\%). For healthy children and CF patients, these figures were $21 \%$ (95\% CI $18-24 \%$ ), and $24 \%$ (95\% CI $10-36 \%$ ), respectively. The slope of NO versus flow was significantly steeper for the asthmatic patients than for the control subjects $(\mathrm{p}=0.003)$. These results were the same, irrespective of whether flow was expressed as $\mathrm{mL} \cdot \mathrm{s}^{-1}$ or as $\% \mathrm{VC} \cdot \mathrm{s}^{-1}$

For each group, whether baseline lung function influenced the outcomes was investigated. It appeared that the NO concentration, NO output and slopes were not significantly affected by either forced expiratory volume in one second (FEV1) or forced vital capacity (FVC). The asthmatic patients who used steroids $(n=13)$ had NO levels that were slightly lower, but not significantly different from those without steroids. Within groups, age did not correlate with exhaled NO values.

Normalizing flow for lung and airway size by expressing it as a percentage of $\mathrm{VC} \cdot \mathrm{s}^{-1}$ instead of $\mathrm{mL} \cdot \mathrm{s}^{-1} \mathrm{did}$ not reduce the standard deviation of the intercepts of the individual regression lines at an arbitrary flow of $7 \% \mathrm{VC}$. $\mathrm{s}^{-1}$ or $300 \mathrm{~mL} \cdot \mathrm{s}^{-1}$ within groups (fig. 2 ).

\section{Discussion}

The present study confirms that the NO concentration in exhaled air rises with decreasing flow, and shows that the $\mathrm{NO}$ /flow relationship differs between children with asthma on the one hand, and CF patients and healthy children on the other hand. The clinical implication of these results is that the measurement of NO clearly distinguished between the different disease states at low flow rates, and that not only NO concentration at a fixed flow rate, but also the slope of the $\mathrm{NO} /$ flow relationship discriminates between asthmatics and healthy subjects or CF patients.

This study is the first to quantify the effect of varying the flow rate on the NO concentration in exhaled air in children and to establish the effect of different disease states on the $\mathrm{NO} /$ flow relationship. SiLKOFF et al. [6] recruited a group of healthy adult volunteers (age 16-50 yrs) for their study of the flow-dependency of end-expiratory NO in exhaled air. SATO et al. [11] studied the effect of the duration of exhalation on the NO levels in exhaled air in healthy and asthmatic adults. Exhaled air was collected in a reservoir and the subjects wore a noseclip. Hence, not only the plateau level of NO, but also the initial peak level, and probably contamination with nasal air contributed to the results of this study. BYRNES et al. [12] studied the mean peak concentration of NO at different flow rates in adults. However, peak NO concentrations reflect the NO concentration in the anatomical dead space, contaminated by nasal NO; noseclips may have enhanced nasal contamination. The increase of NO in exhaled air with decreasing flow observed in the current study matches the results by SILKOFF et al. [6] and BYRNES et al. [12], and confirms that the NO levels in exhaled air in well-controlled asthmatics are only slightly higher than in healthy subjects.

The results of the present study might have been biased by methodological aspects. Firstly, it could be argued that the flow resistance used was not high enough to close the soft palate, leading to nasal contamination. In a study in adults, no contamination of $\mathrm{NO}$ from the nasal cavity was observed with a flow resistance of at least $3 \mathrm{cmH}_{2} \mathrm{O} \cdot \mathrm{L}^{-1} \cdot \mathrm{s}$ [13]. No similar studies have been published for children. The flow resistance used in the current study was 20 $\mathrm{cmH}_{2} \mathrm{O} \cdot \mathrm{L}^{-1} \cdot \mathrm{s}$, and it is therefore likely that nasal contamination of the $\mathrm{NO}$ concentration in exhaled air was effectively prevented at least at flow rates $>150 \mathrm{~mL} \cdot \mathrm{s}^{-1}$, corresponding to oral pressures $>3 \mathrm{cmH}_{2} \mathrm{O} \cdot \mathrm{L}^{-1} \cdot \mathrm{s}$. However, the mean flows at $2 \%$, and sometimes at $5 \%$ of $\mathrm{VC} \cdot \mathrm{s}^{-1}$ were below this value, and therefore some nasal contamination at the lowest flows cannot be excluded. 

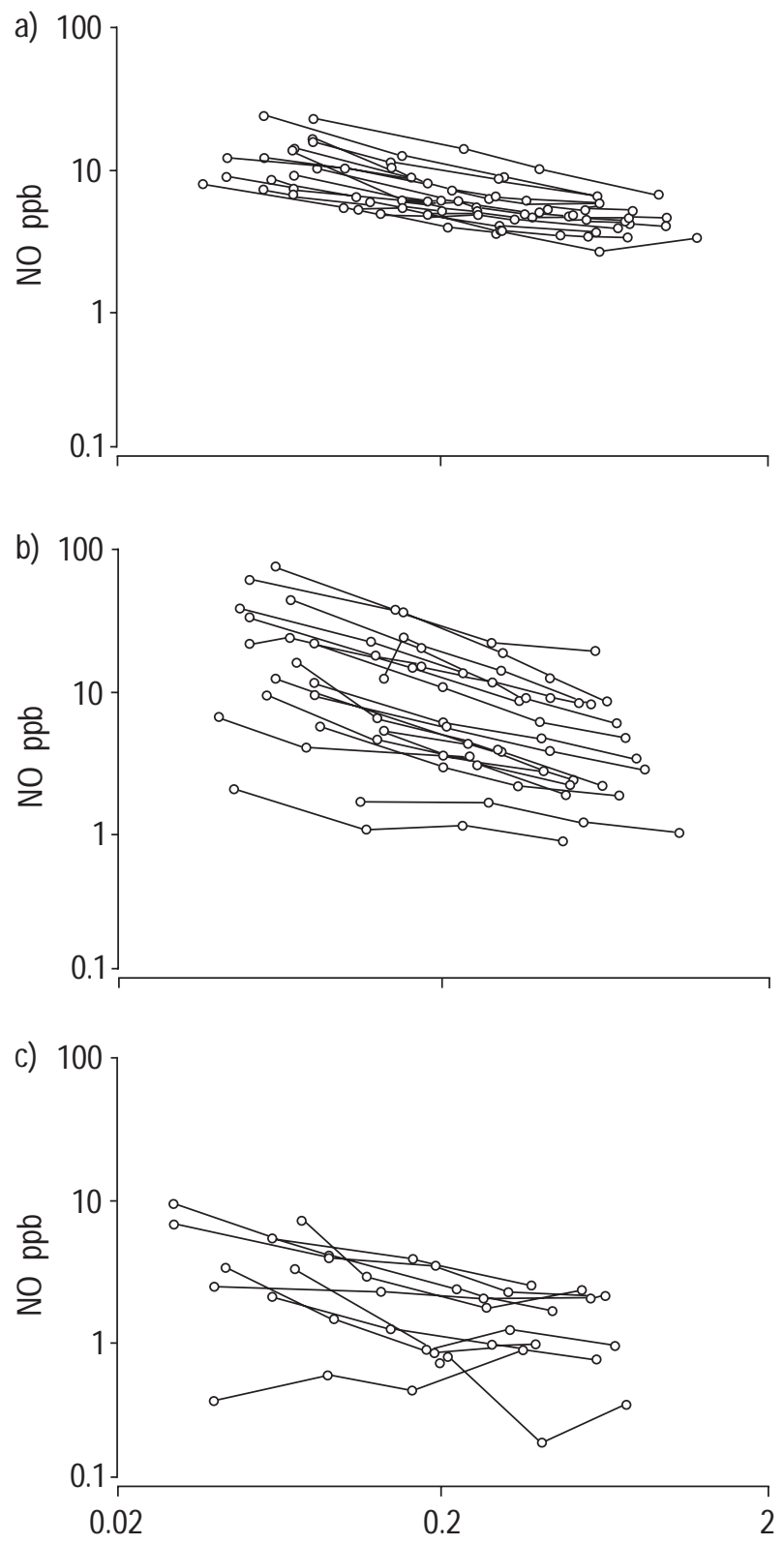

Flow $L \cdot \mathrm{S}^{-1}$

Fig. 1. - Exhaled nitric oxide (NO) versus flow endexpiratory plateaus in a) healthy children $(n=20), b)$ children with asthma $(n=19)$ and $c)$ children with cystic fibrosis $(\mathrm{n}=10)$. Each line represents one child. Both exhaled NO and endexpiratory flow were measured on a logarithmic scale. ppb: parts per billion.

This has not necessarily introduced a bias, as it would affect results in asthmatic and control subjects similarly.

Secondly, the study assessed whether normalizing expiration flow as a percentage of the patient's VC has advantages above comparing fixed flows, which do not take differences in lung and airway size into account. The results showed that normalization of expiration flow for the $\mathrm{VC}$ is not very important when comparing exhaled NO in children of different sizes. It may still be that in larger groups within-group variation is smaller with measurement at a lung size-dependent flow, but this remains to be

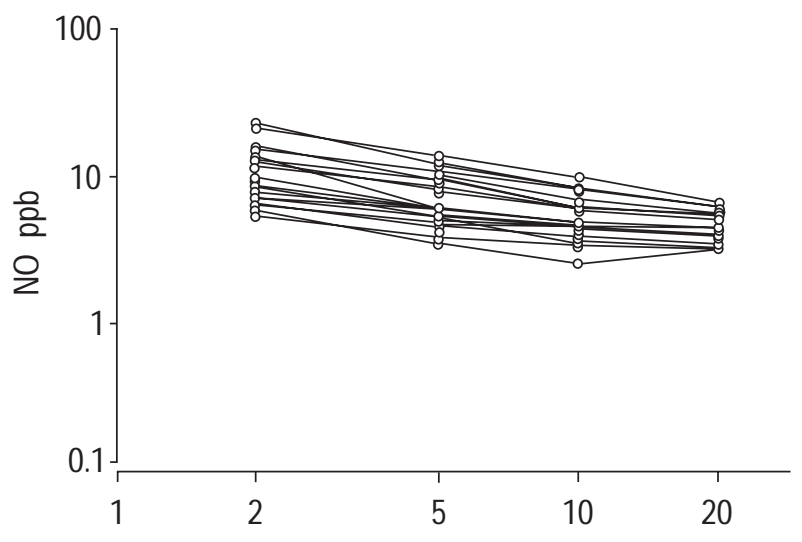

Flow $\%$ VC. $\mathrm{s}^{-1}$

Fig. 2. - Log-log transformed plots of exhaled nitric oxide (NO) of 20 healthy children versus flow normalized as a percentage of the patients' vital capacity (VC) per second. Comparison with fig. 1a shows that normalization of flow for lung size did not result in a reduced variation, confirmed by statistical analysis, showing a similar standard deviation of the intercepts of individual regression lines at arbitrary flows of $7 \%$ of $\mathrm{VC}$ and $300 \mathrm{~mL} \cdot \mathrm{s}^{-1}$ (see Results section.)

shown. Alternatively, standardizing for the lung volume at which NO is measured may increase the accuracy of NO measurements. However, the present study did not explicitly define the lung volume at which results were obtained.

A final source of error may be the repeated performance of expiratory manoeuvres. All children performed a number of deep inspirations and expirations and, since this study, it has been shown that forced manoeuvres cause a decreased NO output [14]. The NO levels may therefore have been underestimated. It is thought that such an effect may have been small, as no decreasing trend was obvious for the repeated measurements at a given target flow.

The group of children with asthma had a higher median level of NO in exhaled air, which may be due to residual chronic airway inflammation despite steroid treatment, and to the fact that a number of children did not use steroids and, indeed, tended to have higher $\mathrm{NO}$ values than those who did.

CF patients have lower exhaled NO than healthy subjects. As inflammation is invariably present in $\mathrm{CF}$ airways [15], it has been speculated that the increased amount of thick bronchial mucus in patients with $\mathrm{CF}$ may favour retention and metabolism of NO in airway liquids [4]. That increased NO production takes place in CF airways is supported by data demonstrating increased nitrite levels in breath condensate, despite normal NO in exhaled air, in a group of older CF patients [16]. The results of the present study confirm that increased NO levels in inflamed CF airways are not reflected by an increase in exhaled NO $[3,4,16]$. In contrast to earlier reports, significantly lower orally exhaled NO values in CF than in control subjects were found. This may partly be due to important differences in methodology: no expiratory resistance [4], tidal breathing versus single controlled expiration [3] and older, more severe patients [16] in previous studies. 
In conclusion, this study shows that differences in exhaled nitric oxide between asthmatics, cystic fibrosis patients and healthy children are greatest at low flows; the linearized NO/flow relationship is steepest in asthmatics. These results indicate that accurate standardization of low flow rates is necessary; a convenient target flow could be $100 \mathrm{~mL} \cdot \mathrm{s}^{-1}$. For firm recommendations, larger groups should be studied and a cutoff level determined for a given purpose, e.g. detection of disease. For diagnostic purposes in children, nitric oxide measurements in exhaled air at different flow rates may prove an additional new tool for the differential diagnosis of airway diseases, especially asthma and cystic fibrosis.

\section{References}

1. Lundberg JON, Weitzberg E, Lundberg JM, Alving K. Nitric oxide in exhaled air. Eur Respir J 1996; 9: 26712680 .

2. Gustafsson LE, Leone AM, Persson MG, Wiklund NP, Moncada S. Endogenous nitric oxide is present in the exhaled air of rabbits, guinea-pigs and humans. Biochem Biophys Res Commun 1991; 181: 852-857.

3. Lundberg JON, Nordvall SL, Weitzberg E, Kollberg H, Alving K. Exhaled nitric oxide in pediatric asthma and cystic fibrosis. Arch Dis Child 1996; 75: 323-326.

4. Balfour-Lynn IM, Laverty A, Dinwiddie R. Reduced upper airway nitric oxide in cystic fibrosis. Arch Dis Child 1996; 75: 319-322.

5. Kharitonov SA, Barnes PJ. Effect of pressure and flow on measurement of exhaled and nasal nitric oxide. Am $J$ Respir Crit Care Med 1997; 155; 4: A825.

6. Silkoff PE, McClean PA, Slutsky AS, et al. Marked flowdependence of exhaled nitric oxide using a new technique to exclude nasal nitric oxide. Am J Respir Crit Care Med 1997; 155: 260-267.
7. Kharitonov SA, Alving K, Barnes PJ. E.R.S task force: Exhaled and nasal nitric oxide measurement: recommendations. Eur Respir J 1997; 10: 1683-1693.

8. Warner JO, Götz M, Landau LI, et al. Management of asthma: a consensus statement. Arch Dis Child 1989; 64: 1065-1079.

9. Zapletal A, Samanek M, Paul T. Lung function in children and adolescents: Methods, reference-values. Basel; Karger Verlag 1987; 191-197.

10. BMDP Statistical Software manual. Unbalanced repeated measures models with structured covariance matrices. University of California Press, Berkeley, 1992; 13301335.

11. Sato K, Sakamaki T, Sumino H, et al. Rate of nitric oxide release in the lung and factors influencing the concentration of exhaled nitric oxide. Am J Physiol 1996; 270: L914-L920.

12. Byrnes CA, Dinarevic S, Busst CA, Shinebourne EA, Bush A. Effect of measurement conditions on measured levels of peak exhaled nitric oxide. Thorax 1997; 52: 697-701.

13. Kharitonov SA, Barnes PJ. Nasal contribution to exhaled nitric oxide during exhalation against a resistance or during breath-holding. Thorax 1997; 52: 540-544.

14. Deykin A, Halpern O, Massaro AF, Drazen JM, Israel E. Expired nitric oxide after bronchoprovocation and repeated spirometry in patients with asthma. Am J Respir Crit Care Med 1998; 157: 769-775.

15. Konstan MW, Hilliard KA, Norvell TM, Berger M. Bronchoalveolar lavage findings in cystic fibrosis patients with stable, clinically mild lung disease suggest ongoing infection and inflammation. Am J Respir Crit Care Med 1994; 150: 448-454.

16. Ho LP, Innes JA, Greening AP. Nitrite levels in breath condensate of patients with cystic fibrosis is elevated in contrast to exhaled nitric oxide. Thorax 1998; 53: 680684. 